\title{
I Seminário Interamericano de Direito Municipal (*)
}

\author{
Yves De Oliveira
}

\section{A IDÉIA DE SUA REALIZAÇÃo}

A idéia da realização de um Seminário Americano de Direito Municipal surgiu de uma troca de impressões que mantivemos com o Dr. Carlos M. Morán, no «Hotel Rex», no Rio de Janeiro, após o IV Congresso Nacional de Municipios, em maio de 1957, antes do regresso dêsse líder cubano ao seu país.

Agora, nesse momento, temos a grata oportunidade de ocupar a presidência dêste certame científico, a fim de, em parte, cumprirmos o delineado no Rio de Janeiro. Tínhamos em vista, quando apresentamos a sugestão ao Secretário da Comissão Pan-Americana de Municípios, em face de nossos modestos contatos e experiência em congressos nacionais e internacionais. conciliar o espirito das reuniões de sentido genérico, promovidas pelas entidades interamericanas, com a necessidade de estudo e análise de certos problemas especializados, que estavam, e ainda estão, a merecer o carinho dos debates restritos é técnicos. Era êsse o nosso pensamento. Era essa a nossa meta.

\section{A RAZÃO DO TEMA ESCOLHIDO}

E por que escolheu-se, com decisão e firmeza, o tema Direito Municipal ? Não foi nem poderia ser por acaso. Ao contrário, fruto do amadurecimento no estudo, na análise $e^{\prime}$ na sistematização dêsse novo ramo do Direito, que estava a necessitar de reuniões como esta que em tão boa hora concretiza-se. A realidade jurídica americana precisa encontrar no meandros do Direito Municipal uma formulação unitária e uma evolução cientifica ajustada aos seus preceitos doutrinários e práticos. Não podemos evoluir tão só com contatos e trocas de informações de sentido pessoal e através da bibliografia específica. Temos que encontrar outros métodos de intercâmbio e de reuniões. Uma fonte mais direta e preciosa para que e'sta evolução do Direito Municipal se dê de maneira unitária e de sentido universal. Se já no âmbito dos Congressos Interamericanos de Advogados a

(*) Oração proferida como Presidente do I Seminário Interamericano de Direito Municipal, realizado em São Paulo, na Escola de Sociologia e Política no dia 5 de novembro de 1958. 
matéria tem sido tratada com certo destaque, não seria admissível que no meio municipalista não alcançasse, como alcança, o grau de desenvolvimento e de valorização que está a merecer por parte dos estudiosos e técnicos nesse setor especializado de Direito.

\section{ALGUNS ANTECEDENTES HISTÓRICOS}

Pelo ano de 1945, começávamos a estudar com objetivo de rigorosa sistematização o Direito Municipal. É preciso, talvez, um pouco de história, com o propósito de situar bem claro como se deu no Brasil a evolução dêsse novo ramo do Direito. Muito menos por amor à vaidade, do que realmente, em nome de uma análise, se bém que superficial, dos fatos e das lutas empreendidas em defesa dessa tese, isto é, da aceitação da autonomia cientifica e didática do Direito Municipal. A batalha foi no comêço cheia de dúvidas e incompréensões. A consciência jurídica clássica atuou com espirito de defesa dessa mesma cultura inconformada coni a evolução do Direito. Nunca, ou muito raramente, êsse novo ramo de Direito apareceu na literatura especializada até então. As nossas Faculdades de Direito adotando métodos clássicos e um espírito nesse setor nitidamente conservador. O próprio Direito Administrativo sem alcançar um grau de evidente desenvolvimento. O Direito Constitucional estagnado, dentro dos seus preceitos históricos. As Ciências das Finanças sem ter ainda conseguido projetar-se como hoje sé encontra. A reação deveria ser uma fatalidade histórica da época e das condições de evolução do ensino e da cultura jurídica do momento. Felizmente nós já ultrapassamos esta fase. Não é que já tenha vencido todos os percalços do caminho. Todavia, grande parte dêle foi ultrapassado pela renovação das idéias e pela evolução social e comunitária.

Em fevereiro de 1946 ofereciamos ao país a primeira edição da «Revista de Direito Municipal». (1) Era a primeira pedra talvez dêsse magnifico edifício em construção. Agora que se apresenta com matizes de envelhecimento, a tese que defendiamos era mais do que revolucionária para alguns, naquela época, apesar também de têrmos tido a generosa acolhida de per sonalidades das mais eminentes do país e do estrangeiro, destacadamente dos Professôres Alcides Greca e Adriano Carmona Romay.

Entre tantos comentários de apoio à revista que fundamos, especialmente por parte, no Brasil, dos estudiosos paulistas, não poderíamos deixar de recordar o de GRECA, intitulado «Una Nueva 'Tribuna del Derecho Municipal». Nesse seu depoimento o mestre argentino de logo mostrou-se fiel aos seus próprios ideais e sensível aos anseios localistas dos povos americanos. Era o Professor eminente da cátedra de Direito Municipal da Faculdade de Direito de Santa Fé, na Argentina, - o tratadista de maior renome e a figura de maior autoridade nessa seara, - acompanhado sempre com essa não menos magnífica expressão de valor que é o Professor Adriano CARMona Romay, titular da cadeira de «Govêrno Municipal», da Universidade de Havana, em Cuba, a nos estimularem na jornada de defesa da tese no Brasil, da autonomia científica e didática do Direito Municipal.

(1) «Revista de Direito Municipal», fevereiro de 1946. Salvador, Bahia, Brasil. 
Sabem os que nos ouvem quanto é ingrata até certo ponto a tarefa dos pioneiros. O seu sofrimento $e$ as incompreensões para contribuirem pelas mudanças de comportamentos e de atitudes no meio cientifico e social. Por outro lado, apresenta-se também aos pioneiros uma alegria e um confôrto incalculáveis quando a vitória sorri, brota da coragem de enfrentar os reacionários, os incrédulos de tôdas as eras e os inadaptados dé todos os tempos. Para os sonhadores que realizam, que pensam que realizam melhor sonhando, às vêzes a reação constitui um estimulante admirável. Cai diante dos idealistas, dêsses sonhadores impenitentes, a máscara de muitos e se afirma e positiva a beleza do caráter, o valor da inteligência, a expressão real da cultura e o profundo sentido de encantamento, de espiritualidade, de estética e dé sensibilidade humana.

\section{O DECÊNIO DOS POSTULADOS DO MUNICIPALISMO AMERICANO}

Em 1948 Àlcides GreCA é convidado a fazer conferências na Bahia, no Rio de Janeiro e em São Paulo. Após a sua última conferência em Salvador, na velha e centenária cidade baiana, teve a oportunidada de ler o Manifesto que juntos elaboramos, denominado «Postulados do Municipalismo Americano». Êsse Manifesto configurou-se como um aspecto verdadeiramente révolucionário na sua época, pois continha, como contém, principios orientadores da nova posição do Direito Municipal e do Municipalismo. Comemoramos, hoje, o seu decênio, agqui em São Paulo, como há dias fizemos na Bahia, e, precisamente faremos no dia em que completar dez anos de lançamento dêsse Manifesto, no Rio de Janeiro em pleno VII Congresso Interamericano de Municípios.

Os «Postuladios do Municipalismo Americano» foram elaborados no «Pálace Hotel», na Bahia, em um momento em que a evolução do pensamento mun cipalista e de valorização do Direito Municipal era ainda incipiznte no meio brasileiro. Teve êsse Manifesto uma repercussão continental merecedora de registro. Na Argentina, Iuís L. Boffr, um dos lideres do Movimento Municipalista, acompanhado por Carlos Mouchet, Salvador Dana Montaño e Beatriz Dalurzo, fêz uma fundada análise acêrca do mesnıo, assim concluindo as suas observações: (2) «Estamos en Visperas de la gran Revolución Social que hará a los hombres más humanos y más justos. Los Postulados do Municipalismo Americano formam parte integral de ella. A la lucha, pues, con optimismo por el porvenir de la Humanidad».

O «Instituto de Estudos Municipais Alcides Greca», entidade fundada em 16 de abril de 1957, em Rosário, na Argentina, no dia em que completava um ano de falecido o seu Patrono, no art. $2^{\circ}$ dos seus estatutos, assim dispõe : «Constitui o objetivo fundamental do «Instituto de Estudos Muricipais Alcides Greca» propiciar a plenitude de ação e desenvolvimento para as comunidades municipais, propugnando e defendendo como o desideratum nesta matéria a implantação efetiva na organização institucional argentina e americana dos «Postulados do Municipalismo Americano»...

(2) "Postulados del Municipalismo Americano" - Buenòs Aires - Abril de 1949. 
O Manifesto tem o seguinte teor :

«Postulados do Municipalismo Americano: (3)

Alcides Greca e Yves Orlando Tito de Oliveira na Bahia, Brasil, aos 11 dias de novembro de 1948 .

Considerando :

Que o vigoroso movimento municipalista do Brasil ao manifestar-se triunfante na Constitứção democrática de 1946 , constitui um acontecimento auspicioso para a Comunidade das Nações Américanas, expressam seus votos porque o municipalismo continental se encaminhe para uma plena realização mediante os postulados seguintes:

a) De ondem cientifica e didática

1\%) Que o municipalismo seja considerado como uma ciência Muni cipal autônoma, com metodologia própria.

2:) Que tôdas as Faculdades de Direito e de Ciências Econômicas do Continente incorporem aos seus planos de estudo esta matéria sob a denominação de «Direito e Ciência da Administração Municipal».

3:) Que se criem institutos de altos estudos para peritos em adminis tração municipal e urbanistas planificadoras.

$4^{\circ}$ ) Que todo núcleo urbano seja dotado, sistemàticamente de um plano regulador.

b) De ordem politico-administrativa

1\%) Que se promova uma revisão dos atuais regimes de organização dos podêrés municipais, orientando para sistemas de eficácia, compativeis com a soberania popular.

2.) Que se torne efetiva a autonomia dos municípios, com a minima intervenção dos podêres do Estado, nacional ou regional.

3\%) Que o desideratum dessa autonomia só se poderá conseguir graças aos postulados essenciais, formulados por WiLCOX: a) Liberdade para que os habitantes da cidade determinem as atribuições e a esfera de ação do govêrno local, em harmonia com as atribuições do govêrno estatal; b) liberdade dos habitantes da cidade para estabelecerem sua organização políticoadministrativa (sistema da carta livre): c) liberdade aos habitantes para eleger as autoridades do govêrno local.

c) De ordem econômico-financeira

1.) Faculdade para estabelecer taxas correspondentes aos serviços e atividades a cargo do govêrno local.

2. Gôzo de impostos e rendas genuìnamente municipais.

$3^{\circ}$ ) Faculdade de contrair empréstimos, com o único limite de não comprometer o crédito do Estado nacional.

$4^{\circ}$ ) Gôzo de um patrimônio próprio e intangivel.

(3) «Postulados do Municipalismo Americano» - 11 de novembro de 1948 Salvador, Bahia, Brasil. 


\section{d) De ordem internacional}

10) Que se realizem periòdicamente conferências interamericanas de municipios, cujas recomendações sejam moralmente obrigatórias, em todos os Estados Americanos.

2.) Qué se crie uma união das Cidades da América, que funcione como uma dependência da União Pan-Americana.

Salvador - Bahia - Brasil, 11 de novembro de 1948. - Alcides Greca. - Yves Orlando Tito de Oliveira.

Não seria admissivel que esquecêssemos talvez a maior repercussão dos "Postulados do Municipalismo Americano", qual seja a de ter o eminente professor Adriano Carmona Romay, da Cátedra de "Govêrno Municipal», cé Cuba, colocado êsse Manifesto entre os pontos de aula do programa da cadeira que leciona. Era a voz mais autorizada da atualidade americana na cátedra, a voz de Romay, considerando êsse Manifesto como merecedor de uma análise profunda, em suas lições aos seus discipulos. Cuba, que destaca um «Prêmio Especial Capablanca - Greca", para os melhores alunos da cadeira de "Direito Municipal Comparado", ao lado de serem os estudos locais nesse País considerados como os mais tradicionais e completos em nosso continente, honrou com os seus melhores aplausos o Manifesto que elaboramos com GRECA, e hoje, em terra paulista, tão querida pelo mestre argentino, que lhe dedicou um ensaio "Baianos e Bandeirantes", comemoramos o seu decênio, com os prezados amigos e companheiros do Movimento Munidipalista nas Américas, neste Seminário de Direito Municipal. E recordando Cuba com carinho não poderiamos deixar de lembrar alguns de seus vultos mais eminentes do passado, no estudo do Direito Municipal, "como José Marti, Francisco Carrera Justiz e Ramiro Capablanca.

\section{CRIAÇÃO DA CADEIRA DE DIREITO MUNICIPAL, NO BRASIL}

Foi criada, na Universidade de São Paulo, a cadeira de «Direito Municipals5, em 1954, faltando apenas ato do Governador dêste Estado para indicação de titular. Apelamos para os representantes paulistas no Govêrno, na Universidade e nos meios culturais para que ajudem a pôr em funcionamento a cátedra criada de "Direito Municipal", a fim de contribuirem, decisivamente, para a formação de uma consciência cientifica e didática no País em relação aos problemas do Direito, da Ciência e da Administração Municipais. São Paulo, que tomou a dianteira na matéria, não pode parar. Os seus homens públicos têm a noção exata da evolução do Municipio no Estado Moderno. Esperamos mais esta preciosa contribuição dos paulistas não só ao nosso País, como a todo o Continente Americano.

\section{O PROGRAMA DA CADEIRA DE DIREITO MUNICIPAL}

Outro assunto importante é o programa da cadeira. Como uma modesta colaboração nesse sentido, apresentamos ao IV Congresso Interamericano de Municipios, realizado em Montevidéu, em 1953, um esbôço para as cadeiras 
a serem criadas, especialmente em nosso País. Êsse programa é bem o desdobramento sistematizado dos magnificos programas de GRECA e ROMAY, e que tivemos a oportunidade de inserir em nosso «Curso de Direito Municipal» (4).

\section{A $X$ CONFERÊNCIA INTERAMERICANA DE ADVOGADOS E A SUPERAÇÃO DO CONCEITO DE FEDERALISMO}

A evolução do Estado Moderno tem trazido grandes modificações em certos conceitos do Direito Público. O federalismo é um dêles. A sua superação está já nas constituições de determinados países e na consciência dos povos. Assim notamos na atual Carta Magna do Brasil, de 16 de setembro de 1946. Ela constitui, sem dúvida, uma fonte preciosa dessa evolução do Estado Moderno, que tem de atender às hodiernas tendências descentralizadoras. Uma descentralização política que não chegue ao Município, não mais encarna os anseios dos povos, das Comunidades e dos agrupamentos menos densos. A divisão de esferas de competências politicas e administrativas é uma fatalidade do Estado Moderno. Chegamos a sonhar com a República Municipalista.

Repetimos, aqui, o que já afirmamos em outra oportunidade: (5)

"Em nosso País, o conceito de federação está superado, ou, no mínimo, reformado. Bem sabemos das dificuldades dos autores em conceituar o que seja federação. Todavia, pretendemos situá-lo numa média de opiniões e tendências, como sendo: a descentralização politica e administrativa em dois graus. Reparai bem "em dois graus": a União e os Estados-Membros. Isto é, a Federação, no seu conceito mais ou menos exato. E o Municipio, onde fica nessa Federação? Como acentua Castro Nunes, êste é unitário em relação aos Estados-Membros. Na Federação tal qual se nos afigura dentro do conceito da ciência, o Município não aparece como entidade em detalhe, na organização politica e administrativa do País, isto é, na sua Carta Magna. Veja-se, por exemplo, na Constituição da Argentina e na de outros Paises.

No Brasil, assistimos a sua Constituição Nacional de 1956 incluir até o Municipio entre os principios constitucionais da União. Isto é, senhores municipalistas e juristas, a mais aberrante deturpação do conceito de Federação. O que há no atual regime constitucional brasileiro é uma descentralização em têrmos absolutos, do conceito de Federação, completando-se uma descentralização do Estado Moderno ao máximo. Como quer que seja, na vida hodierna, - Municipio readquire o seu prestígio e determina um conceito de vida que não o desconheça, mas, pelo contrário, o exalte, como o seu próprio fundamento, dentro da civilização moderna, e de acôrdo com as justas aspirações das coletividades".

(4) «Curso de Direito Municipal» - 2" ed. Editôra Freitas Bastso S. A. Rio de Janeiro, 1958, p. 272.

(5) «República Municipalista» - Ric de Janeiro, 1957, p. 8. 


\section{A REPÚBLICA MUNICIPALISTA}

A República Municipalista está sendo estruturada diante da realidade social e politica da civilização moderna. Um mundo novo, diferente em técnica e em métodos industriais, se apresenta ante nós. Não serão os obsoletos processos sociais e politicos que utilizaremos ao encontro dessa nova ordem. Não é possível que num mesmo momento histórico haja tão acentuadas diferenças de civilização dentro de uma mesma área geográfica. Para corrigir essas desigualdades individuais e coletivas teremos que recorrer a um novo mecanismo governamental, capaz de atender a essas novas realidades. O Federalismo, com uma descentralização em dois graus, está em plena decadência. Não satisfaz mais aos anseios dos povos livres. E é nas próprias constituições modernas, como a atual brasileira, a cubana, e outras, que iremos encontrar essa superação federalista. O Municipio elevado a uma categoria constitucional que concorre em competência com a União e os Estados-Membros ou as Provincias, desfigurando, por completo, o conceito de Federação. E' preciso que se tenha a coragem das afirmações, mesmo quando elas representam um desafio ao espírito tradicionalista. O Estado Moderno tem que ser descentralizado ao máximo. Fixemos aquêle concerto de G. E. HowarD: "estudo das instituições locais tem hoje a mesma altura e dignidade que o estudo do Estado".

No VI Congresso Interamericano de Municipios, realizado no Panamá, contribuimos para dar ao Municipalismo um conteúdo filosófico, com o apoio urianime de todos os presentes. (6)

$\mathrm{Na} \mathrm{X}$ Conferência Interamericana de Advogados, realizada em novembro de 1957, en Buenos Aires, conseguimos talvez dar o primeiro golpe, um golpe dirzto no conceito de Federalismo no Continente Americano. E' que se inseriu no setor de Direito Municipal uma declaração, na qual a autonomia municipal deve ser consagrada nos textos das Constituições Nacionais dos Países americanos. Que significa isto senão a morte do Federalismo, o desaparecimento do conceito não diremos clássico, porém contemporâneo do Município como uma organização dos Estados-Membros ou das Provincias? O Município elevado no texto constitucional a uma posição tão alta quanto a Nação, ou a Província ou Estados-Membros, como chamamos no Brasil. Conduzido a essa evolução ou revolução, porque estamos assistindo a mudança total do conceito de federalismo nas Cartas Politicas modernas, com o propósito de situar-se o Município na condição que a vida social moderna impõe, seguindo nesse ponto o conceito de Municipio da escola sociológica tão brilhantemente defendida por Romay.

O Direito Municipal com essa nova orientação toma maior desenvoltura, adquire substância de mais profunda institucionalidade na vida politica dos povos e mais rigor de sistematização cientifica e didática. Neste I Seminário

(6) Ata final da VI Reunião do Congresso Interamericano de Municipíos, publicada na «Revista Municipal Interamericana», p. 2, referente à primeira consideração do tema II, da mencionada Reunião em 1956. 
Interamericano de Direito Municipal firmaremos deliberações do maior interêsse para o desenvolvimento dêsse novo ramo do Direito.

\section{A INFLUÊNCIA DE ALCIDES GRECA}

ALCIDES GRECA conceituou muito bem: "E' no municipalismo que reside a forrça dos povos livres". O mestre argentino foi um consolidador das idéias de sistematização do Direito Municipal na América. Nesta hora de sadias reflexões e confiança no futuro dêsse ramo do Direito, não podemos olvidá-lo. Mais do que isto. Recordá-lo com carinho, com saudades sentidas pelo seu trabalho desenvolvido e pelo seu caráter de homem público. GRECA nunca se dobrou a qualquer tentativa de opressão nem se intimidou com os processos politicos impregnados de obscurantismo. Foi sempre um apóstolo da ciência, um dedicado ao estudo, um amante da liberdade e um livre defensor da democracia. Foi um legítimo mestre da mocidade de sua época. Tinha, ainda, para the completar a personalidade varonil e marcante, a bondade como lema de sua vida. Sabía elevar-se, tanto na altivez, quando necessária, quanto na humildade imposta pelos grandes sentimentos.

Em contato com o povo paulista, amigos e estudiosos do Direito Municipal e do Municipalismo no Continente Americano, saudamos a todos os presentes a esta reunião, que tem o apoio da Escola de Sociologia e Politica, da Magnífica Universidade de São Paulo e da Comissão Pan-Americana de Cocperação Intermunicipal, como parte integrante do programa oficial do VII Congresso Interamericano de Municípios.

Esta reunião póderá ser um marco bem definido no Brasil e em nosso Continente, das modernas tendências valorizadoras e sistematizadoras do Direito Municipal, principalmente quanto à sua autonomia cientifica e didática.

Aparecem, a cada passo, no Brasil, trabalhos dos nossos juristas sôbre êsse novo ramo do Direito. Desejamos destacar, sem dúvida, pela sua maior impcrtância, além de outros trabalhos especializados, o livro de HELY LOPES Meireies - "Direito Municipal Brasilairo"; e de Delorenzo Neto, "Códigos Municipais", porque definem comportamentos científicos visando a completa autonomia do Direito Municipal.

E' com o maior carinho que notamos, nesta reunião, a presença de velhos e queridos amigos da América, além de numerosos companheiros paulistas, e de outros Estados brasileiros, das lutas que vão se tornando velhas, travadas pela renovação das idéias e pelo maior progresso material de bem-estar dos povos americanos.

Com a confiança no futuro, pleno de esperanças de que o Direito Municipal alcançará um grau de evolução unitária em tôda a América, concitamos a todos os presentes nâo esmorecerem no estudo, na pesquisa e na análise de seus fundamentos científicos, porque só com a sua valorização poderemos cntribuir para que a civilização moderna não seja privilégio de um menor número, porém de todo Homem e de tôda Comunidade, num mesmo momento histórico. 


\section{SEMINARIO INTERAMERICANO DE DIREITO MUNICIPAL}

\section{REUNIÃO EM SÃO PAULO}

Contou o I Seminário Interamericano de Direito Municipal, realizado en 5 de novembro de 1958, em São Paulo, na Escola de Sociologia e Política, promovido pela Comissão Pan-Americana de Cooperação Intermunicipal, com a presença dos Srs. Yves de Oliveira (presidente), Antônio Delorenzo Neto (relator-geral), Salvador Dana Montaño (expositor) e Carlos Mouchet, Beatriz Dalurzo, Mário Wagner Vieira da Cunha, Hely Lopes Meireles, Orlando de Carvalho, Silvio Fortunato, Hubo MüLlEli (debctedores) e outros estudiosos do Direito.

\section{TEMA}

O tema debatido foi o seguinte: Direito Municipal e Ciências Sociais (Sistematização - Elaboração - Interrelações).

\section{A EXPOSIÇÃO DO PROF. DANA MONTAÑO}

O professor DANa Montaño encaminhou a discussão do tema, através da compreensão de seus limites, esclarecendo que a sistematização deve referir-se à posição do Direito Municipal no conjunto das ciências juridicas; a elaboração, à forma pela qual cria ou estabelece o Direito Municipal positivo, ou seja, as fontes do seu respectivo conteúdo; e, as interrelações terão por objeto o estudo das vinculações, conexões, auxilios, e etc., que prestam ao Direito Municipal as demais ciências sociais.

A sistematização do Direito Municipal se beneficia de certas distinções fundamentais: Direito Municipal científico e Direito Municipal positivo. O Direito Municipal cientifico é uma parte da ciência do Direito que estuda, em geral, as relações jurídicas de correntes do município, como ente politico de existência necessária. O Direito Municipal científico representa a doutrina que serve à elaboração do Direito Municipal positivo, sendo êste um ramo do Direito Público interno. As relações juridicas decorrentes do fenômeno sociäl "municipio" estão reguladas por princípios peculiares do Direito Público do paîs em que o mesmo se situa.

O govêrno e a administração municipal apresentam analogias e semelhanças muito acentuadas com o govêrno e administração do Estado pròpriamente dito, e de outras entidades superiores -- porém nem sempre anteriores nem mais importantes que o município - na formação histórica de algumas estruturas estatais, como nos países de organização federal. Porēm, apresentam, por outro lado, diferenças fundamentais que repercutem no tratamento científico de seu respectivo objeto : o gênero próximo e a organização fundamental; a diferença específica é o Estado-Membro, ou Província, ou Cantão, ou Lander, e, o Município. A autonomia cientifica que se deve atribuir ao Direito Municipal é uma conseqüência iniludivel de autonomia, que caracteriza o municipio contemporâneo.

O significado e o alcance do atributo de autonomia, em sua evolução conceptual, pode ser examinado no conteúdo das próprias declarações dos 
Congressos Interamericanos de Municipios. Em 1938, no I Congresso, realizado em Havana, assim podemos ler:

«I Congresso Pan-Americano de Municipios declara que considera conveniente assegurar constitucionalmente o princípio da autonomia do município, garantindo de um modo especial a eletividade de seus governantes, a livre percepção e aplicação de suas rendas dentro de sua própria esfera administrativa e financeira, o contrôle jurisdicional de suas decisões e a faculdade de iniciativa e de ação em todos os assuntos relativos a satisfação das necessidades públicas locais.»

Mas precisa, todavia, é a declaração de Montevidéu, em 1953 por ocasião do IV Congresso, em que o têrmo «autonomia deixa de ser meramente convencional, e sim empregado na acepção própria de poder de govêrno, dentro de uma unidade maior, sempre mass extensa e de natureza distinta de uma entidade meramente administrativa, conforme a vinham considerando. Eis o texto de Montevidéu: "1 - Que autonomia municipal se caracteriza pelo reconhecimento na Constituição Nacional: a) da autonomia politica fundada nos princípios democráticos; $b$ ) da capacidade financeira com recursos adequados para o cumprimento de seus fins; c) de administração própria dos serviços públicos locais. 2 - Que o direito e a competência dos governos locais devem emanar do poder constituinte municipal, reconhecido na Carta fundamental do Estado. Portanto, devemos levar em conta que o municipio é, por sua natureza, uma instituição universal, destinada a reger os seus próprios interêsses, que são os da comunidade local, intermediária entre a familia e - Estado, em todos os tipos estatais, inclusive os federais, embora nestes existam outras entidades intermediárias, como o Estado-membro, as Provincias, etc.

Para corroborar êste conceito, o professor DANA MonTAÑo considera conveniente distinguir no municipio três aspectos: 1) natural ou social; 2) formal ou juridico; e 3) ideal ou político.

O $1^{2}$ elemento, natural ou social, nos diz como é o ente municipal; que é, e como é, um município com sua natureza como entidade social; o 2. elemento, formal ou juridico, nos esclarece como deve ser, e como se considera o município em um país determinado, isto é, em sưa legislação positiva. E, o Direito Municipal, comparado, por sua vez, nos dará uma idéia de como deve ser encarado o município, do ponto de vista da organização universal. Em 3: lugar, o ideal ou político pròpriamente dito: como deverá ser o municipio para preencher de modo satisfatório seus fins próprios. E' uma aplicação de sua teoria sôbre a distinção entre a realidade e o ideal na organização do Estado. De acôrdo com êsse ponto de vista, a realidade institucional pode ser natural ou social (como é a infra-estrutura) e jurídica (como deve ser a superestrutura). Seu estudo dá lugar respectivamente à Sociologia Politica e ao Direito Constitucional (realidade presente) e à História Politica ou das Instituições (realidade passada). A "idealidade" (organização ideal) pode ser estudada do ponto de vista puramente teórico 
(Política cientifica) ou Aplicada (prático) (Técnica polítíca ou arte de govêrno). A Política cientifica é a ciência teórica (normativa) que tem pố objeto o estudo das constituições ideais do Estado, isto é, a organização fundamental mais adequada aos fins do mesmo.

Aplicando-se êstes conceitos ao Municipio, estas três ordens de conhecimento dão lugar respectivamente à Sociologia Municipal, ao Direito Municipal e à Politica Municipal (Ciência do govêrno municipal). Não podemos separar êstes três aspectos do Municipio, senão por razões didáticas, pois êles se interrelacionam profundamente.

\section{CONCLUSÕES}

Foram apresentadas e aprovadas as seguintes conclusões :

I - Recomendar às Universidades do continente, a intensificação dos estudos municipais, em todos os seus ramos, ou seja, em seu tríplice aspecto sociológico, jurídico ou político, instituindo cátedras de Sociologia Municipal, Direito Municipal e Govêrno ou Política Municipal, sem prejuízo de manter as existentes de Direito Municipal Comparado, considerada a importância que tem o Municipio para a vida individual, familiar e estatal.

II - Propiciar a autonomia científica do chamado Direito Municipal, pela importância adquirida por seu objeto próprio, como meio de promover a investigação e o ensino sôbre os problemas municipais, e de desenvolver o espirito do autonomismo comunal.

III - Recomendar aos municípios da América o fomento da investigação e do ensino da Ciência Municipal, em seu tríplice aspecto sociológico, jurídico e politico, instituindo centros de estudos, bibliotecas especializadas, institutos docentes e de investigação, bôlsas e prêmios para os estudos municipais.

IV - Ratificar as declarações e recomendações dos Congressos anteriores sôbre o autogovêrno do municipio, proclamando a autonomia do mesmo em seu tríplice aspecto - político, administrativo e financeiro, e delimitando a esfera da mesma, relativamente aos entes públicos maiores (Estados nacionais e particulares, províncias, etc.) reivindicando o reconhecimento expresso das atribuições e faculdades comunais básicas, que integram seu govêrno próprio.

$\mathrm{V}$ - Que se estimule por todos os meios, e principalmente pelo assessoramento indispensável dos técnicos, a colaboração do Direito Municipal científico na elaboração das normas legais, incluindo como assessôres dos legisladores especialistas em Direito Municipal, e estabelecendo legalmente o estudo e informações prévias, pareceres e consultas, informação ao público, quando fôr o cáso, e demais expedientes da moderna técnica legislativa, a fim de que a regulamentação de caráter geral sôbre a matéria municipal assegure a legalidade, acêrto e oportunidade das normas que contenham. 
VI - Recomendar que se intensifique o estudo das ciências sociais relacionadas mais intimamente com a ciência municipal, para assegurar a contribuição das mesmas à elaboração do Direito Municipal, especialmentc das Ciências Politicas e Juridicas, e, em particular, a Sociologia, a Economia, a Politica, o Urbanismo, a Ecologia Humana e a Antropologia Social.

Essas conclusões também foram ratificadas pelo plenário do VII Congresso Interamericano de Municipios, realizado no Rio de Janeiro, de 10 a 16 de novembro de 1958. 